\section{FLORAL PHENOLOGY, SECONDARY POLLEN PRESENTATION AND POLLINATION MECHANISM IN INULA RACEMOSA (ANGIOSPERMS: ASTERACEAE)}

\author{
Peerzada Arshid Shabir ${ }^{1}$, Irshad Ahmad Nawchoo ${ }^{2}$ \& Aijaz Ahmad Wani ${ }^{3}$ \\ ${ }^{1,2,3}$ Economic Botany and Reproductive Biology Laboratory, Department of Botany, University of Kashmir, Srinagar, \\ Jammu and Kashmir 190006, India \\ ${ }^{1}$ peerzadarshid@gmail.com (corresponding author), ${ }^{2}$ irshadnawchoo@yahoo.co.in, ${ }^{3}$ aijazbotku@gmail.com
}

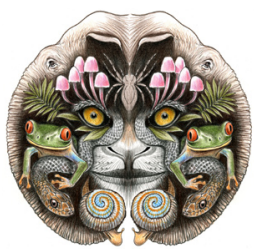

ISSN

Online 0974-7907

Print 0974-7893

OPEN ACCESS
Abstract: Inula racemosa Hook. f. is protandrous, discharges pollen grains inside the anther tube and presents pollen secondarily onto the sweeping hairs of the style. The style and stigmatic branches present the yellow clumped pollen grains for pollination. This study describes floral functional morphology and phenology, anther dehiscence and pollen presentation, growth and behaviour of style during anthesis and pollination mechanism of I. racemosa. The species is entomophilous and is characterized by a highly asynchronous sexual phase. A large degree of asynchrony from floret to floret in a capitulum, and capitulum to capitulum in a plant, keeps the pollen dispersed for a longer duration. Two insect families were represented in the pollinator survey: Hymenoptera and Diptera. A significant correlation was observed between the number of capitula visited per bout and foraging time. We discuss morphological features of the flowers which may enhance the pollen removal rate per bee visit and consequently cause a high visitation and pollination rate.

Keywords: Breeding system, Inula racemosa, phenology, pollination, secondary pollen presentation

Flowering plants possess exceptionally versatile mating strategies which are governed by distinctive features of the biology and ecology of the group. Since mating strategies employed by a group influence the movement of genes in space and their transmission through time, they play a fundamental role in determining spatial and temporal patterns of genetic diversity within and between populations, and hence their evolutionary dynamics. Because of their immobility, plants require vectors to transfer pollen, giving rise to diverse floral adaptations which are widely recognized to influence floral organization, patterns of pollen dispersal, pollinating agents involved and these reproductive traits comprise the key elements of the mating strategies of flowering plants.

In angiosperms, individuals potentially compete to donate pollen to receptive stigmas. Because of this, sexual selection can shape functional floral characters (Bell 1985; Queller 1997). The structural variation in flowers and inflorescences and different mechanisms for deployment of male and female gametes is remarkable when one considers that their sole function is to promote reproductive success. Analysis of any plant community reveals a variety of pollination and mating systems that coexist under apparently similar ecological conditions. Male and female gametes are deployed in various structural and temporal combinations at the flower, inflorescence, plant or population level. Morphological and phenological aspects of floral design and display primarily influence the quantity and quality of pollen dispersal during the pollination process. Several functional or adaptive floral traits, such as protoandry, self-incompatibility, herkogamy and secondary pollen presentation, have evolved to avoid or minimize the

DOI: http://dx.doi.org/10.11609/JoTT.03320.4498-503

Editor: Cleofas Cervancia, University of Philippines Los Baños College Laguna, Philippines.

Date of publication: 26 June 2013 (online \& print)

Manuscript details: Ms \# 03320 | Received 26 August 2012 | Final received 08 May 2013 | Finally accepted 09 May 2013

Citation: Shabir, P.A., I.A. Nawchoo \& A.A. Wani (2013). Floral phenology, secondary pollen presentation and pollination mechanism in Inula racemosa (Angiosperms: Asteraceae). Journal of Threatened Taxa 5(10): 4498-4503; http://dx.doi.org/10.11609/JoTT.03320.4498-503

Copyright: (C) Shabir et al. 2013. Creative Commons Attribution 3.0 Unported License. JoTT allows unrestricted use of this article in any medium, reproduction and distribution by providing adequate credit to the authors and the source of publication.

Funding: Council of Scientific and Industrial Research, Pusa, New Delhi.

Competing Interest: None.

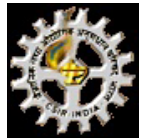

Acknowledgements: The first author is highly thankful to CSIR for providing financial assistance in terms of JRF fellowship during this study. 
effects of self-interference and thus improve outcrossing rates.

Inula racemosa Hook. f., commonly known as "Pushkarmoola" of family Asteraceae is distributed from temperate to sub-alpine belts, the species has been categorized as rare according to the Red Data Book of Indian plants (Nayar \& Sastry 1988.). The species is entomophilous with 10-20 capitula per plant aggregated in racemes. Disc florets of $I$. racemosa are protandrous and have a peculiar mechanism of secondary pollen presentation. In protandrous flowers male and female function is temporally separated and pollen is presented before the stigma becomes receptive. Protandry is common in outcrossing angiosperms (Lloyd \& Webb 1986) and is often assumed to be selected for avoidance of self-fertilization.

Secondary pollen presentation is the developmental relocation of pollen from the anthers onto another floral organ which then functions as the pollen presenting organ for pollination (Howell et al. 1993) and the phenomenon has traditionally been described as a mechanism that enhances the efficiency and accuracy of pollen exportation and/or pollen reception, thus increasing male and/or female fitness of the plant (Ladd 1994). Diverse methods have evolved for secondary pollen presentations with pollen being presented onto the style (Nyman 1993), in specialized regions of the style or stigma (Westerkamp \& Weber 1997), or even over the stigmatic area (Imbert \& Richards 1993), usually before flower opening. In I. racemosa, however, pollen is shed onto the sweeping hairs of the style prior to floret anthesis and the style subsequently elongates to display the pollen. Thus, in I. racemosa pollen is presented by the style and stigmatic branches before the stigma completely exposes the two layers of receptive papillae cells which marks the entry of a floret into the functionally female phase. To provide information on the basic reproductive biology of $I$. racemosa, we initiated this study using laboratory and field approaches to investigate: (i) floral functional morphology; (ii) anther dehiscence and pollen presentation (iii) growth and behaviour of style during anthesis; and (iv) pollination mechanism (Image 1).

\section{Material and Methods}

Study area: The study was performed during April 2009 to November 2010 on two main study sites, i.e., Gulmarg $(2650 \mathrm{~m})$ and Farozpora $(2150 \mathrm{~m})$, lying at a distance of $50-60 \mathrm{~km}$ to the west of Srinagar City. In addition, one transplanted population was established and monitored at Kashmir University Botanical Garden
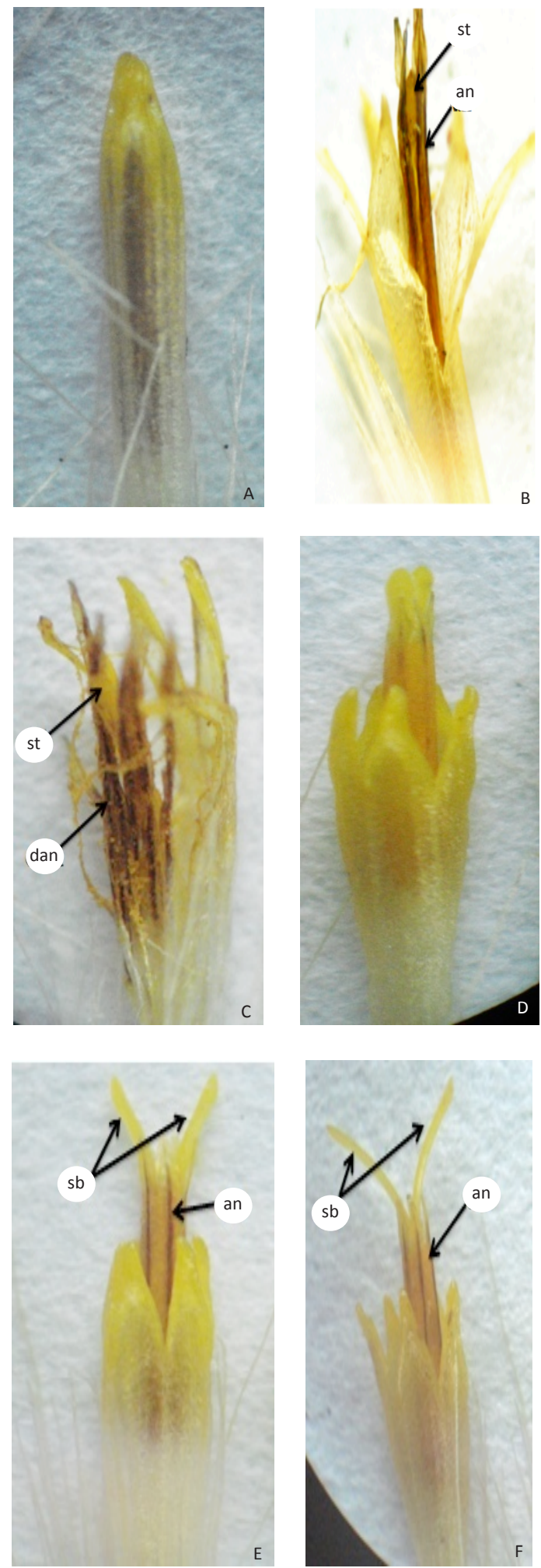

Image 1. A - Early floral stage showing floret is beginning to open; B - Dissected floret showing anther (an) and stigma (st);

C - Dissected floret showing anther dehiscence (dan); D - Floret just opened; $E$ - The stigma branches growing out of the anther tube.

F - The stigma branches (sb) expose the stigmatic surfaces and the anthers (an) are dry, brown and withering.

(C) Peerzada Arshid Shabir 
(KUBG-1595 m).

Floral morphology and phenology: Morphometric analyses were performed on several capitula by collecting the samples from flower buds to capitula at anthesis and observed under a dissecting microscope. The capitula were examined for the spatial and temporal arrangement of male and female sexual parts within the ray and disc florets. Various floral phenological stages were identified according to the development and relative location of ray and disc florets within a capitulum. Macro images of floral features were captured using a stereo microscope.

Stigma receptivity:Stigmas at different developmental stages of selected plants were assessed for receptivity by fixing stigmas of different ages in Carnoy's fixative, followed by staining in $1 \%$ lactophenol analine blue. The stigmas with germinated pollen grains were recorded as receptive and the number of germinated pollen grains on the stigma was taken as an index of the degree of receptivity.

Pollination mechanism: To unravel the pollination mechanism operative in the species, the foraging behaviour of various insects visiting the flowers for pollen and nectar was monitored. The frequency of insect visitation was observed during different periods of a day. The insect visiting efficiency was calculated as:

$$
\text { IVE }=\frac{\text { No. of flowers visited by an insect in one bout }}{\text { Total no. of flowers available }}
$$

During the foraging bout of honeybees, three variables were recorded: the number of capitula visited on the plant, the time spent foraging on each of these inflorescences and the total time spent per plant and during the whole bout. Wherever possible, the plant at which the honeybee next foraged was also recorded.

\section{Results}

Flowering phenology: The vegetative phase of the species is followed by a highly asynchronous sexual phase. Among the different populations studied, the transplants growing at relatively low altitudes were the first to enter the sexual phase during the $3^{\text {rd }}$ week of May and continued the floral bud formation up to $4^{\text {th }}$ week of June. However, the high altitude natural populations enter the sexual phase late during $3^{\text {rd }}$ or $4^{\text {th }}$ week of June and the completion of bud initiation is witnessed up to $1^{\text {st }}$ or $2^{\text {nd }}$ week of August.

The species shows a large asynchrony in anthesis from floret to floret in a capitulum, plant to plant in a population and across populations growing in varying habitats. The transplants were the first to depict anthesis during the $2^{\text {nd }}$ week of June which continued up to $2^{\text {nd }}$ week of July. Among the natural populations, anthesis started in the $2^{\text {nd }}$ or $3^{\text {rd }}$ week of July and continues till $3^{\text {rd }}$ or $4^{\text {th }}$ week of August. Each capitulum enters anthesis with maturation of outer single whorl of pistillate ray florets which surround multiple whorls of disc florets. After expansion of the ray florets that coincides with lateral expansion of the inflorescences, the protandrous disc florets develop distally and sequentially in whorls. Disc florets mature from the periphery of the capitulum to the centre. All the florets of a capitulum open within 5-8 days and all the capitula of a plant open within 1820 days.

Floral organisation: In I. racemosa each capitulum possesses a single outer whorl of ray florets and multiple inner whorls of disc florets. Ray florets are yellow, gynoecious and zygomorphic. Disc florets are actinomorphic; about $2.42 \pm 0.54 \mathrm{~cm}$ in length, perfect, having both androecium and gynoecium. The corolla is in the form five fused petals, the tips of which can be distinguished at the upper margin of the corolla tube. The androecium is composed of five stamens. Anthers are sagitate and fused into a tube while the filaments remain free. The bifid stigma has long "sweeping" trichomes on the non-receptive surface that collect and trap pollen grains from the interior of the anther tube and present them for pollination. Expansion of the stigmatic lobes signifies the beginning of the female phase. The receptive surface of the stigma is covered with stigmatic papillae. The stigma lobes were equal in length but shorter than the style.

Pollen emission and stigma receptivity: The disc florets of $I$. racemosa are hermaphroditic, with five anthers fused together to form a tube and the stigma and the style grow through the centre of the tube. Before anthesis of florets, the anthers dehisce inwardly and discharge pollen grains inside the anther tube onto the sweeping hairs of the style but the stigma is not yet receptive. As the anther dehiscence proceeds, the carpels develop further and begin to elongate through the tube and the pollen grains get adhered to the sweeping hairs of the style branches. The style and stigmatic branches thus present the yellow clumped pollen grains for pollination but the stigma branches are still joined. From day 3-5 of anthesis, the style grows to its full length and the two stigmatic branches completely open, while the anthers become dry and brown and begin to wither. The stigma completely exposes the two layers of receptive papillae cells which marks the entry of a floret into the functionally female phase. The stigma remains receptive for three to four days after 
which stigmatic surface begins to shrivel that marks the end of receptivity.

\section{Pollination mechanism}

During the flowering period, several insect species were observed visiting the flowering heads of $I$. racemosa. A large degree of asynchrony from floret to floret in a capitulum and capitulum to capitulum in a plant keeps the pollen dispersed for a longer duration and thus attracting the insects again and again to pollinate a number of florets. Two insect families were represented in the pollinator survey, including Hymenoptera and Diptera. However, honeybees (Apis indica) accounted for the highest number and duration of visits for all the populations studied and thus was considered a major pollinator for the species. The bees were observed to become active early in the morning and remain in the field till late evening. The mean number of inflorescence visited per plant/bee ranged from $2.53 \pm 0.71$ at Gulmarg to $4.18 \pm 0.43$ at Farozpora. However, the terminal capitula were significantly more visited than axillary ones and the period of greatest insect activity was from 12:00-16:00 hr, coinciding with maximum temperatures. The mean honeybee foraging time per capitulum was $39 \pm 3.0 \mathrm{~s}, 37 \pm 7.0 \mathrm{~s}$ and $48 \pm 6.0 \mathrm{~s}$ and the mean foraging times per plant were $152 \pm 7.54 \mathrm{~s}$, $128 \pm 9.07$ s and $142 \pm 13.69$ s at Farozpora, Gulmarg and KUBG respectively. Also, a significant correlation was observed between the number of capitula visited per bout and foraging time.

Other insect visitors that were also observed foraging on I. racemosa though less frequently included several species of butterflies, Xylocopa spp., flies and wasps. These insects generally have foraging behaviours similar to honeybees but were observed to visit the plant capitula at very low frequency (Fig. 1).

\section{Discussion}

Flowering phenology is a developmental process crucial to determine the plant reproductive success. The divergence of flowering times among species and populations can have important evolutionary consequences such as reduction of interspecific pollination (McNeilly \& Antonovics 1968; Waser 1978). In the present study, the different populations of Inula racemosa studied along the altitudinal gradient differed significantly for dates of onset and commencement of various phenophases. High altitude Gulmarg population $(2650 \mathrm{~m})$ emerged and started sprouting 12 days later than comparatively low altitude populations at Farozpora $(2150 \mathrm{~m})$ and Farozpora $(2150 \mathrm{~m})$ populations
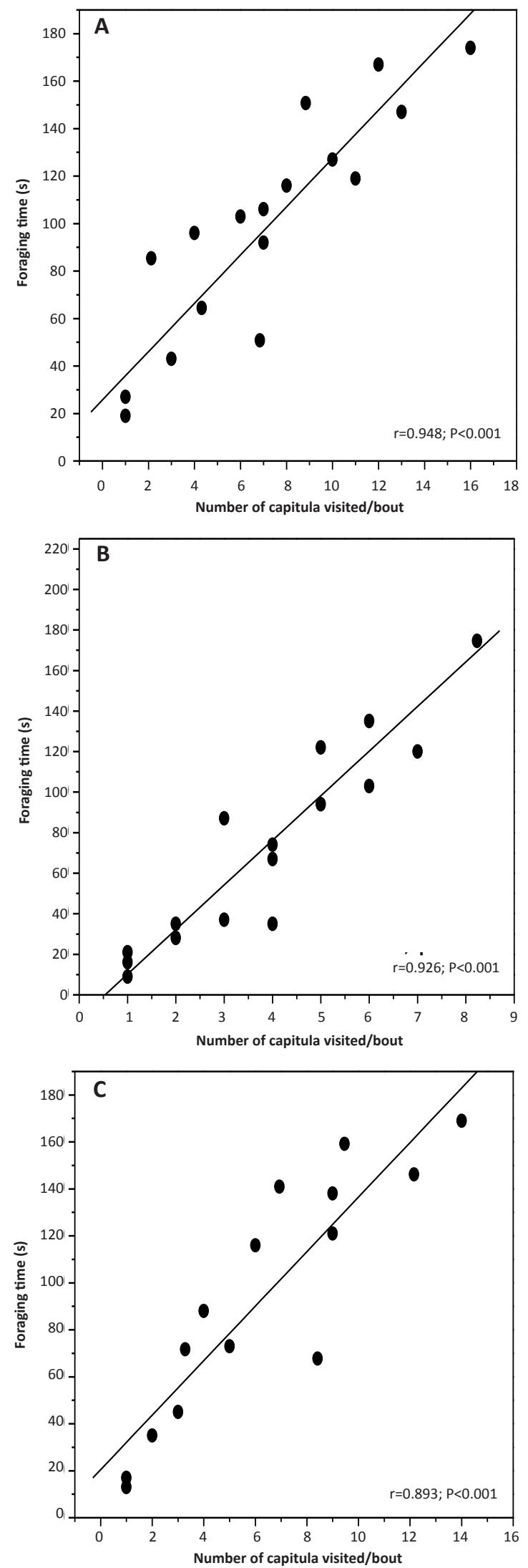

Figure 1. Correlations between the number of inflorescences visited per bout and foraging time among $I$. racemosa plants at the three studied populations (A) Farozpora (B) Gulmarg and (C) KUBG 
emerged 28 days later than low altitude populations at KUBG (1595m). Bud phenology of the plants started in $2^{\text {nd }} 3^{\text {rd }}$ or $4^{\text {th }}$ week of June in natural populations and lasted for 39-48 days. In transplanted populations bud sprouting initiated in $3^{\text {rd }}$ week of May and lasts up to 35 days. The inflorescence (capitulum) enters anthesis with maturation of the outer, single whorl of ray florets and the protandrous disc florets developed distally and sequentially in whorls. Disc florets matured from the periphery of the capitulum to the centre. One to two whorls of mature florets reached anthesis per day. To complete the anthesis within all florets of a capitulum, it takes 5-8 days and within all the capitulla of a plant about 20-30 days. This asynchronous anthesis ensures the long term availability of pollen to certify effective pollination as also supported by Wyatt (1982). Variations in degree of flowering asynchrony within populations and consequent fitness effects have also been shown in a number of circumstances. The timing of flowering with respect to conspecific neighboring plants can potentially affect the seed set of individual flowers (Allen 1986), total plant seed production (Schmitt 1983), seed quality (Marquis 1988), and timing of seed dispersal (Lacey \& Pace 1983). Flowering asynchrony within populations may also reduce intraspecific competition for pollinators and promote outcrossing (Rogstad 1994).

Flower is the structure directly involved with pollinator attraction and its morphological and functional traits affect the reproductive success of the plant. Thus, floral features may have great importance in narrow endemic species (Navarro \& Guitian 2002). Our observation has shown that the floral morphology of $I$. racemosa is especially adapted for insect attraction and the outer colourful "petal-like" ray florets of the capitula attract insects usually but typically lacking an androecium and are the first to reach anthesis followed soon by the outermost whorl of disc florets. Pollinators are rewarded by inner disc florets in the staminate phase (pollen and nectar) preceding the pistillate phase. This developmental sequence is a mechanism employed to prevent autogamy (Kevan 1997). Receptive surface of the stigma get exposed by the reflexing of the stigmatic lobes in the receptive pistillate phase. Bilobed stigmas are a typical feature of the asteracean gynoeciums (Mani \& Saravanan 1999) and gynoecia of $I$. racemosa do not differ from this asteracean convention. I. racemosa stigmas serve a dual purpose; in the staminate phase the stigma is utilized as a secondary pollen presenter and in the pistillate phase the stigma serves its more conventional purpose of a receptive surface for pollen. This type of active pollen presentation is typical of asteracean disc florets (Ladd 1994). The stigma lobes reflex in the pistillate phase to expose their receptive papillae.

Secondary pollen presentation is the result of functional and/or adaptive features of the flower which enhance the placement of pollen onto the pollination vector (Inouye et al. 1994; Ladd 1994). Secondary pollen presentation system is widespread in angiosperms (Howell et al. 1993). It has been described as a strategy to improve accuracy in pollen removal and deposition, which will result in the enhancement of the male and female fitness (Ladd 1994) and this mechanism, seems to occur within Campanulaceae and Asteraceae by means of stigmatic lobes curvation (Cerana 2004). Our observations show that $I$. racemosa is protandrous and the pollen is shed from the anthers onto the sweeping hairs of the style in the bud stage when the style branches are joined and stigmatic surfaces are not receptive. This is consistent with the observations on some other species of Asteraceae (Roitman 1999; Carana 2004). As the style grows out of the anther tube, the outside of the style branches presents pollen for pollination. The receptive papillate stigmatic surface is hidden between the two appressed style branches, preventing self pollination. After the pollen presentation, during the functionally female phase of the floret, the style branches separate completely and the two layers of receptive papillae on the adaxial surfaces become receptive by day $4-6$. From day seven onwards flower enters the senescence stage when the two style branches bend towards the centre of the floret.

In $I$. racemosa the florets are protandrous and consequently favour vector mediated crossing. The two families of insects documented as pollinators in the present investigation include Hymenoptera and Diptera with a major pollinator being species of Apis in all the study sites. The Apis and Bombus pollinated members of Asteraceae are well documented by several workers like Wyatt (1982), Lawrence (1985). Since a number of floral visitors were observed to visit the capitula of the species and this spatial and temporal heterogeneity found in $I$. racemosa visitors may suggest that, in this species, the process of generalization would be favoured instead of specialization. The different studied populations of I. racemosa differ significantly in all total measures of foraging behaviour for honeybees, the major pollinator. Plants varied specifically with respect to the numbers of honeybee visits and honeybee foraging behaviour (the number of capitula visited, the foraging time per inflorescence and the foraging time per plant). Furthermore, a consistent pattern with respect to plant 
preferences (the plants visited most often) was observed, e.g., plants inhabiting the shady habitats of Farozpora received the lowest levels of honeybee foraging visits compared to other populations. This is inconsistent with the some previous studies which have reported the variation in the availability of sunlight influence the pollinator visits and reproductive success (Herrera 1995). Rathcke \& Real (1993) also reported that fruit set of Kalmia latifolia was not limited by inadequate pollination in sunny field sites, but was pollination limited in the shaded forest site. This will clearly affect the production of offspring and thus, the introduction of new individuals into the populations each year.

\section{REFERENCES}

Allen, G.A. (1986). Flowering pattern and fruit production in the dioecious shrub Oemleria cerasiformis (Rosaceae). Canadian Journal of Botany 64: 1216-1220; http://dx.doi.org/10.1139/b86-165

Cerana, M.M. (2004). Flower morphology and pollination in Mikania (Asteraceae). Flora 199: 168-177; http://dx.doi.org/10.1078/03672530-00145

Herrera, C.M. (1995). Plant-vertebrate seed dispersal systems in the mediterranean: ecological, evolutionary and historical determinants. Annual Review of Ecolological Systematics 26: 705-727.

Howell, G.J., A.T. Slater \& R.B. Knox (1993). Secondary pollen presentation in angiosperms and its biological significance. Australian Journal of Botany 41(5): 417-438; http://dx.doi. org/10.1071/BT9930417

Imbert, F.M. \& J.H. Richards (1993). Protandry, incompatibility, and secondary pollen presentation in Cephalanthus occidentalis (Rubiaceae). American Journal of Botany 80: 395-404.

Inouye, D.W., D.E. Gill, M.R. Dudash \& C.B. Fenster (1994). A mode and lexicon for pollen fate. American Journal of Botany 81(12): 1517-1530.

Kevan, P.G. (1997). Pollination biology and plant breeding systems, pp. 59-83. In: Shivanna, K.R. \& V.K. Sawhney (eds.). Pollen Biotechnology for Crop Production and Improvement. Cambridge University Press.

Lacey, E.P. \& R. Pace (1983). Effect of parental flowering and dispersal times on offspring fate in Daucus carota (Apiaceae). Oecologia 60(2): 274-278; http://dx.doi.org/10.1007/BF00379533
Ladd, P.G. (1994). Pollen presenters in the flowering plants: form and function. Botanical Journal of the Linnaean Society 115: 165-195; http://dx.doi.org/10.1111/j.1095-8339.1994.tb01777.x

Lawrence, M.E. (1985). Senecio L. (Asteraceae) in Australia: Reproductive biology of a genus found primarily in unstable environments. Australian Journal of Botany 33(2): 197-208; http:// dx.doi.org/10.1071/BT9850197

Mani, M.S. \& J.M. Saravanan (1999). Pollination ecology and evolution in Compositae (Asteraceae). New Hampshire Science Publishers, USA, 154pp.

Marquis, R.J. (1988). Phenological variation in the neotropical understory shrub Piper arieianum: causes and consequences. Ecology 69: 1552-1565.

Mcneilly, T. \& J. Antonovics (1968). Evolution in closely adjacent plant populations. IV. Barriers to gene flow. Heredity 23: 205-218; http:// dx.doi.org/10.1038/hdy.1968.29

Navarro, L. \& J. Guitian (2002). The role of floral biology and breeding system on the reproductive success of the narrow endemic Petrocoptis viscosa Rothm (Caryophyllaceae). Biological Conservation 103: 125-132; http://dx.doi.org/10.1016/S00063207(01)00108-2

Nyman, Y. (1993). The pollen-collecting hairs of Campanula (Campanulaceae). 2. Function and adaptive significance in relation topollination. American Journal of Botany 80: 1437-1443.

Rathcke, B. \& L. Real (1993). Autogamy and inbreeding depression in Mountain Laurel, Kalmia latifolia (Ericaceae). American Journal of Botany 80: 143-146.

Rogstad, S.H. (1994). Biosystematics and evolution of the PolyalthiaHypoleuca species complex of Malesia 3. Floral ontogeny and breeding systems. American Journal of Botany 81: 145-154.

Roitman, G.G. (1999). Pollination biology of Grindelia covasii (Asteraceae), a potential crop for arid lands. Journal of Arid Environments 43: 103-110; http://dx.doi.org/10.1006/ jare.1999.0531

Schmitt, J. (1983). Individual flowering phenology, plant size, and reproductive success in Linanthus androsaceus, a California annual. Oecologia 59: 135-140; http://dx.doi.org/10.1007/BF00388084

Waser, N.M. (1978). Competition for humming bird pollination and sequential flowering in two Colorado wild flowers. Ecology 59: 934-944

Westerkamp, C. \& A. Weber (1997). Secondary and tertiary pollen presentation in Polygala myrtifolia and allies ( Polygalaceae, South Africa). South African Journal of Botany 63: 254-258.

Wyatt, R. (1982). Inflorescence architecture: how flower number, arrangement and phenology affect pollination and fruit set. American Journal of Botany 69: 585-594. 